\title{
Editorial: Segmenting the Future of E-Commerce, One Step at a Time
}

\author{
María Teresa Ballestar \\ ESIC Business \& Marketing School, Madrid, Spain, mariateresa.ballestar@esic.edu \\ Co-Editor \\ May 2021
}

\section{Introduction}

Currently, customer segmentation is one of the most relevant and powerful tools for explaining customer behaviour in e-commerce and enables brands to develop personalized acquisition and retention strategies for each cluster rather than generic, one size fits all strategies that are no longer valid. Segmentation strategies show marketers how to deal with different customers with diverse characteristics to achieve such goals as strengthening their loyalty or increasing their contribution to the brand, etc. Undoubtedly, this is a key to success in highly competitive environments where the specific product or service has little or no differentiation among competitors and is looking for a competitive advantage [7].

On top of that, the second digital wave has developed disruptive technologies such as Big Data that, correctly adopted by companies, are able to provide large amounts of valuable data about customer behaviour [12]. This data correctly processed and analysed using data science methods such as machine learning, allows for the development of different data strategies that include novel dynamic multivariate segmentations. The development of the traditional segmentation methods provides companies with a longitudinal perspective in the evolution of the segments of customers, as it adds the variable of time to the models [1].

Can these tools devise marketing strategies? What can we expect to obtain from them? Will they be able to illustrate processes like the customer journey or predict the expected outcomes of marketing strategies?. I will try to respond to such questions that explain the use of technology, computer sciences, and statistics for marketers who want to develop efficient strategies [4], [15].

\section{Relational Marketing and Customer Segmentation}

The increase of consumer control and empowerment provide an enriched sense of satisfaction once the clients make their choices [17]. Marketing strategies have been involved in facing this new environment, going from product centric strategies to a new paradigm of a customer centric strategy. This new relationship focusses not exclusively on the financial transactions but also in establishing profitable long-term relationships for both players [11], [16], [18]. As a result, marketing based on relationships seeks costs effectiveness. In the new framework, the relationship between consumer and seller leverages key aspects that allow for an efficient customer response at every touch point on the customer journey, favouring its retention and finally, its advocacy.

These shifts in marketing orientation provide a better response to customer expectations and needs. As a result, customer segmentation becomes a fundamental tool for grouping customers depending on variables that allow for the application of personalized acquisition and retention strategies rather than generic ones, which would be less effective, enabling companies to increase customer loyalty and long-term profitability [2].

\section{Digital Transformation Across Industries}

The birth of new business ecosystems has had a massive impact on both brands and customers. It is true that the adoption of digitalization has not happened at the same pace across industries because many different factors are involved in the process of digitalization. These factors are sector specific but, in all cases, imply, at least, a considerable structural and cultural transformation that will force the company to change from the inside out. If the transformation is correct, employees and staff will be impacted much earlier than customers within this process of transformation: its success lies in empowering the employees to embrace the transformation [3].

One of the key factors of this change is the need for product or brand differentiation among competitors. Those companies working in a more competitive and global landscape with little or no differentiation among their competitors adopt digitalization as a way of setting themselves apart. Segmentation enables companies to reach and impact their target customers with personalized products and communications when the customer perceives that it is the right moment or situation, and also standardizing the operative processes towards a more efficient model.

As an example, the health care sector, was characterized in past by a high market concentration with a model based on the added value of face to face activities because of the intrinsic characteristics of their customers and their products with differentiated attributes [13]. Now, the increasing fragmentation of the market, lower profit margins, and the 
entrance of the digital generation into the portfolio of customers, has pushed the transformation of this kind of industries too. These sectors are running towards digitalization, benefiting from the insights and learning generated by other industries and also attracting external talent to speed up the knowledge transfer to the industry [6], [8].

\section{Big Data, Machine Learning and Customer Segmentation}

The second digital wave has provided the companies with large quantities of data generated by the customers in real time. But it also has provided the technologies, such as Big Data, which allow for processing, storing and analysing almost any kind of data in real time too. This has boosted the application of disciplines such as machine learning, a combination of statistical and computational theories of learning processes algorithms that are now commonly used for finding customer patterns, which will help companies to solve complex business questions of any kind by analysing massive volumes of online data [14].

In this new scenario, Big Data and machine learning extend the application of traditional customer segmentation methods to e-commerce. Customer segmentation methods now benefit from the $4 \mathrm{~V}$ 's which define the characteristics of Big Data: Availability of big Volume of data stored in the cloud which makes sample selection procedure more robust and easier to perform avoiding undesired biases. Variety of the data gathered that fully captures the customers' characteristics and the possible activities and behaviour that they show on the websites. The data can be processed and analysed in real time providing Velocity to the evaluation and classification of the customers into segments. This facilitates the personalization of communication between the customer and the brand, which is able to trigger the right message at the right moment. Finally, Veracity, which refers to the added quality of the data that is fully accessible and more reliable thanks to the automation processes that avoid human intervention and manipulation. This is an important aspect to consider, as business decisions with big impact on financial results will be taken based on customer segmentation in e-commerce [9].

Customer segmentation methods benefit also from the evolution of enriched machine learning methods in two complementary dimensions. The first consists of methods that can manage large and rich datasets of customers' characteristics, behaviour and transactions, with both qualitative and quantitative variables, that are candidates to be included in the customer segmentation model. The second comprises the development of methods that are able to segment customers in a dynamic longitudinal view over time (using a data sample collected over time). By adding the time variable to segmentation, these methods not only show the classification of the customers into groups at a specific moment in time, but are able also to depict their evolution over time drawing the customer journey between one segment to the next one in their path from acquisition to being an advocate of the brand [1]. Hence, the more advanced the segmentation methods the more benefits are provided for business decision making. Empirical research shows how accessing large audiences in e-commerce forces the companies to deal with more different groups of customers. For example, in [2] eight different clusters of target customers were managed designing different marketing strategies according to their characteristics, giving a $2,947 \%$ difference between the most profitable group of customers and the least profitable one.

Information Communication Technologies (ICTs) bring major benefits to society but their extensive usage is also showing downsides. Some of them were expected and others have risen unexpectedly and are indeed, very varied. They range from privacy issues, the risks of unconscious or conscious bias of IA algorithms, to even the sustainability and environmental costs, etc. For example, the amount of electric power needed by Information Technology (IT) infrastructures will be $21 \%$ of the global demand for electricity in 2030 [10].

\section{Conclusions}

Customer segmentation in e-commerce is a strategic and powerful tool. It offers a competitive advantage against competitors in an increasingly competitive environment. There is plenty of new opportunities for practitioners and academics. Mixed methods of cross section and longitudinal research, real time applications or the constructions of new and more robust algorithms, tested through triangulation are only a few of the new opportunities [1], [2], [19].

To take full advantage of this research, companies require structural and cultural transformation. Also, the implementation and adoption of these advanced segmentation methods will require a good knowledge and understanding of Big Data technologies and disciplines such as machine learning. The scope of marketers and their needed skills will evolve from being more creative to more technical and analytical. In addition to this, it will be necessary to create specific departments of advanced analytics to work collaboratively with marketers and decision makers and collaboration will rise with specialized third parties that will help with the development and adoption of these technologies and methods. The massive volume of data from the internet and the capacity to manage all this information to get knowledge from it will provide the brands valuable insights for understanding the increasingly complex customer behaviour in e-commerce [5]. 


\section{References}

[1] M. T. Ballestar, L. M. Doncel, J. Sainz, and A. Ortigosa-Blanch, A novel machine learning approach for evaluation of public policies: An application in relation to the performance of university researchers, Technological Forecast and Social Change, vol. 149, p. 119756, 2019.

[2] M. T. Ballestar, P. Grau-Carles and J. Sainz, Customer segmentation in e-commerce: Applications to the cashback business model, Journal of Business Research, vol. 88, pp. 407-414, 2018.

[3] H. Boutetière, A. Montagner, A. Reich. (2018, October) Unlocking success in digital transformations. McKinsey. [Online]. Available: https://www.mckinsey.com/business-functions/organization/our-insights/unlocking-successin-digital-transformations

[4] J. M. Cavanillas, E. Curry and W. Wahlster, New Horizons for a Data-Driven Economy: A Roadmap for Usage and Exploitation of Big Data in Europe, European Commission 2016.

[5] S. Erevelles, N. Fukawa and L. Swayne, Big Data consumer analytics and the transformation of marketing, Journal of Business Research, vol. 69, no. 2, pp. 897-904, 2016.

[6] M. Herrmann, P. Boehme, T. Mondritzki, J. P. Ehlers, S. Kavadias, and H. Truebel, Digital transformation and disruption of the health care sector: Internet-based observational study, Journal of Medical Internet Research, vol. 20, no. 3, p. e104, 2018.

[7] S. D. Hunt and D. B. Arnett, Market segmentation strategy, competitive advantage, and public policy: Grounding segmentation strategy in resource-advantage theory, Australasia Marketing Journal, vol. 12, no. 1, pp. 7-25, 2004.

[8] T. Janowski, Digital government evolution: From transformation to contextualization, Government Information Quarterly, vol. 32, no. 3. pp. 221-236, 2015.

[9] X. Jin, B. W. Wah, X. Cheng, and Y. Wang, Significance and challenges of big data research, Big Data Research, vol. 2, no. 2, pp. 59-64, 2015.

[10] N. Jones, How to stop data centres from gobbling up the world's electricity, Nature, vol. 561, no. 7722, pp. 163$166,2018$.

[11] P. Kotler, Presentation at the Trustees Meeting of the Marketing Science Institute in November 1990. Mimeo. Boston, MA, 1991

[12] L. Li, T. Chi, T. Hao and T. Yu, Customer demand analysis of the electronic commerce supply chain using Big Data, Annals of Operation Research, vol. 268, no. 1-2, pp. 113-128, 2018.

[13] A. Mädche, Interview with Wolfgang Gaertner, digitalization in retail banking: Differentiation and standardization through IT, Business Information System Engineering, vol. 57, no. 1, pp. 83-85, 2015.

[14] T. M. Mitchell, The discipline of machine learning. Vol. 9. Pittsburgh: Carnegie Mellon University, School of Computer Science, Machine Learning Department, 2006.

[15] T. B. Murdoch and A. S. Detsky, The inevitable application of big data to health care, Journal of the American Medical Association, vol. 309, no. 13. pp. 1351-1352, 2013.

[16] J. N. Sheth and A. Parvatiyar, The evolution of relationship marketing, International Business Review, vol. 4, no. 4, pp. 397-418, 1995.

[17] L. Wathieu, L. Brenner, Z. Carmon, A. Chattopadhyay, K. Wertenbroch, A. Drolet, and G. Wu, Consumer control and empowerment: A primer, Marketing Letters, vol. 13, no. 3, pp. 297-305, 2002.

[18] F. E. Webster, The changing role of marketing in the corporation, IEEE Engineering Management Review, vol. 21, no. 3, pp. 48-60, 1993.

[19] Z. Yao, P. Sarlin, T. Eklund, and B. Back, Combining visual customer segmentation and response modeling, Neural Computing Applications, vol. 25, no. 1, pp. 123-134, 2014. 